\title{
TECHNIQUE OF VENTILATION DURING ENDOLARYNGEAL SURGERY UNDER GENERAL ANAESTHESIA
}

W.E. SPOerel, M.D., F.R.C.P.(c) aNd R.E. GreenWay, M.D., F.R.C.s. (C)

IN MICROSCOPIC ENDOLARYNGEAL SURGERY the surgeon and the anaesthetist are competing for the airway. The surgeon requires a quiet field under his operating microscope which the anaesthetist can only provide with difficulty in a spontaneously breathing patient. The compromise of a small cuffed endotracheal tube in a paralysed patient introduces some obstruction to the surgeon's working area. The technique of apnoeic oxygenation provides ideal conditions for the endoscopist, but is hazardous in view of the accumulation of carbon dioxide and imposes a limitation on the duration of surgery.

Adequate pulmonary ventilation combined with excellent conditions for microscopic surgery can be produced by applying the Venturi injector principle directly to the human trachea using a technique of transtracheal ventilation described recently by Spoerel and others ${ }^{5}$ and Jacobs. ${ }^{2}$

\section{Theoretical Considerations}

A jet of oxygen or air introduced in an axial direction into the trachea will produce a positive pressure in the portions of the airway distal to and a transient negative pressure in those proximal to the jet (Figure 1). When the glottis is open, air will be entrained, leading to a more rapid filling of the lungs. On interruption of the jet, passive expiration will take place.

In a simple model, consisting of an endotracheal tube representing the trachea and an anaesthetic breathing bag, the pressure changes generated by the jet can be readily demonstrated (Figure 2 ). With prevention of air entrainment by a oneway valve, the pressure in the trachea below the jet will rise to a plateau, while the pressure in the trachea proximal to the jet becomes initially briefly negative, then returning to zero. Once the pressure plateau has been attained in the lower airway excess gas will emerge through the upper trachea and glottis, generating a slightly positive pressure which depends upon the resistance to outflow in the upper airway. In an open-ended tube, air entrainment will obviate the negative pressure phase. In spirometric measurements in dogs, the volume of air entrainment was found to be about 40 per cent of the tidal volume. ${ }^{2}$

The pressure gradient between the upper and lower trachea (i.e., proximal and distal to the jet) is determined by the volume flow from the jet and consequently directly proportional to the pressure applied to the jet (Figure 3).

The pressure generated by a given volume flow emerging from the jet is inversely proportional to the cross sectional area of the trachea in an exponential

\footnotetext{
-Departments of Anaesthesia and Otolaryngology, University of Western Ontario and Victoria Hospital, London, Canada.
} 


\section{2}

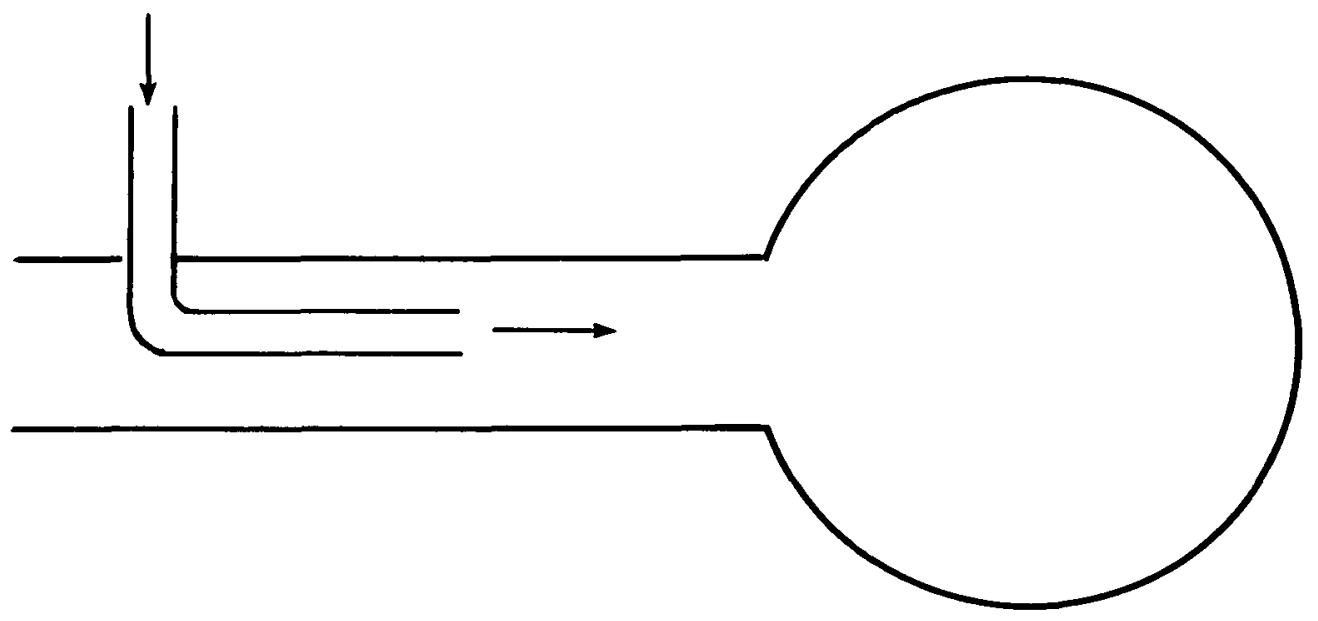

FIGURE 1. Diagramatic illustration of jet injector.

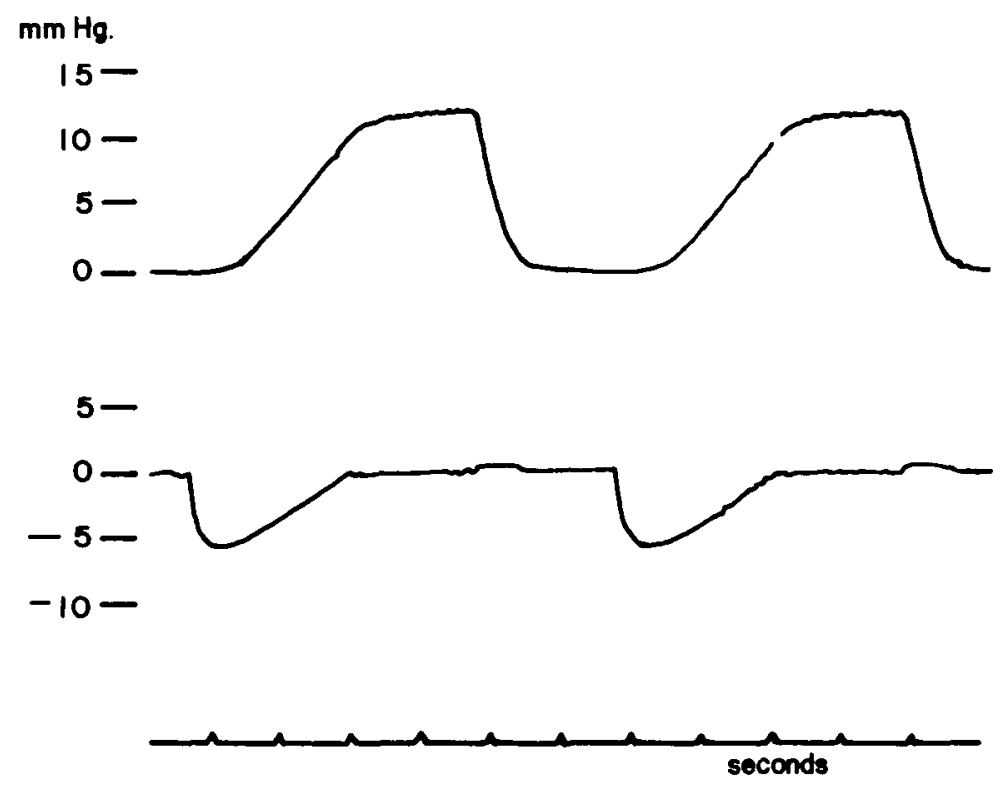

Figure 2. Pressure tracing distal (upper) and proximal (lower) to jet in a model as described in the text. Air entrainment was prevented by a one-way valve.

fashion (Figure 4). Since the cross sectional area of the adult human trachea falls within the flat portion of this curve, this factor only moderately influences the pressure generated. However, a jet with the same volume flow introduced into the smaller trachea of a child can generate dangerously high pressures. In children either lower pressures must be used or a jet with a smaller orifice. 


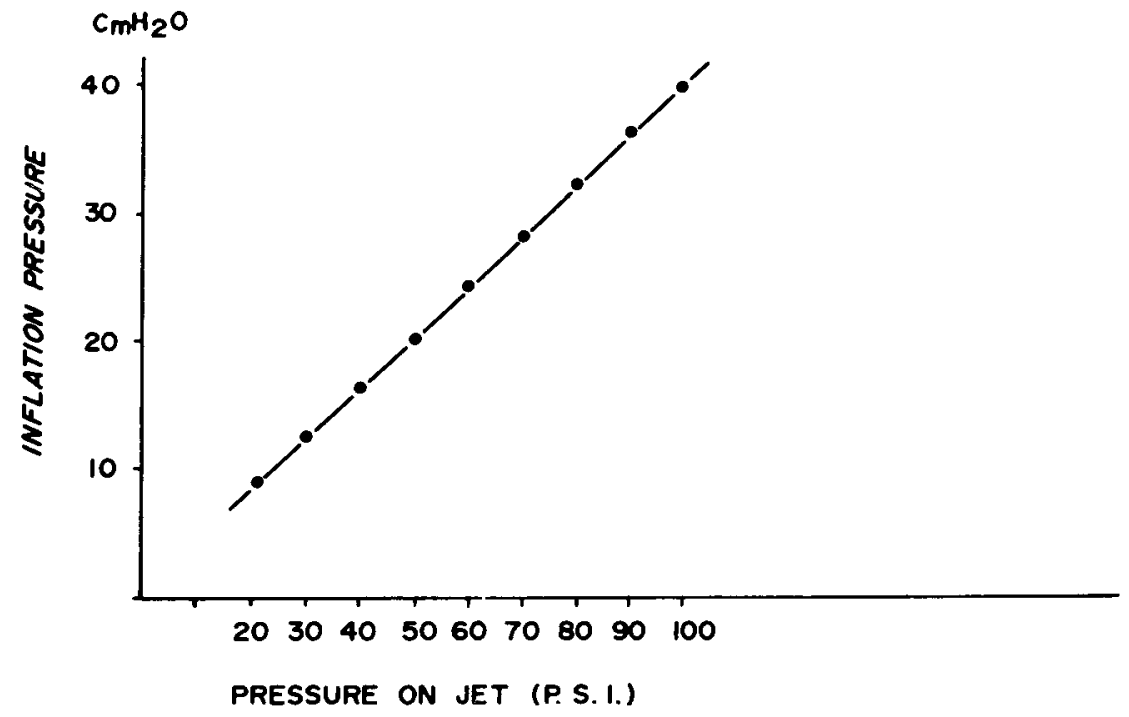

Figure 3. Relationship between pressure applied to the jet in pounds per square inch and inflation pressure obtained (in $\mathrm{mmHg}$ ) in a model experiment.

\section{Introduction of the Jet}

For ventilation during endolaryngeal surgery the jet can be introduced into the trachea in two ways: Either transtracheally by puncture of the trachea with a plastic needle $e^{2, \tilde{5} .6}$ or by nasotracheal intubation with a plastic catheter. For the transtracheal approach a 14- or 16-gauge plastic needle with a steel needle as stilette, commonly used for intravenous infusion, has been employed. A number 260 polyethylene tubing, $50 \mathrm{~cm}$ in length and attached to a 15-gauge needle has been used as a nasotracheal jet. The distance of $5 \mathrm{~cm}$ from the tip of this catheter is marked with one ring and a distance of $10 \mathrm{~cm}$ with two rings. In order to facilitate manipulation of this fine catheter, it is slipped into a $30 \mathrm{~cm}$ length of disposable 14-gauge suction catheter.

Prior to use, perforations are made near the tip of the catheter or the plastic needle, either with the tip of a 20 -gauge needle or a small dagger point scalpel. ${ }^{2}$ If the end of the catheter should come to rest against the mucous membrane so that it becomes occluded, gas will escape through these side holes with sufficient force to free the tip from the point of obstruction, thus avoiding damage to the tracheal mucosa.

\section{Transtracheal Jet}

The patient is given a sleeping dose of thiopentone. When unconscious, a small pillow is placed under the shoulders and the head is maximally extended. The cricoid cartilage is then palpated and fixed between the index and middle finger of the left hand. A 14- or 16-gauge plastic needle, firmly attached to a $5 \mathrm{ml}$ syringe is then introduced, puncturing the skin between the middle and index finger of the left hand at the lower edge of the cricoid cartilage, and advanced at an angle of $45^{\circ}$ towards the trachea. A slight snap is usually felt when the trachea is entered. 


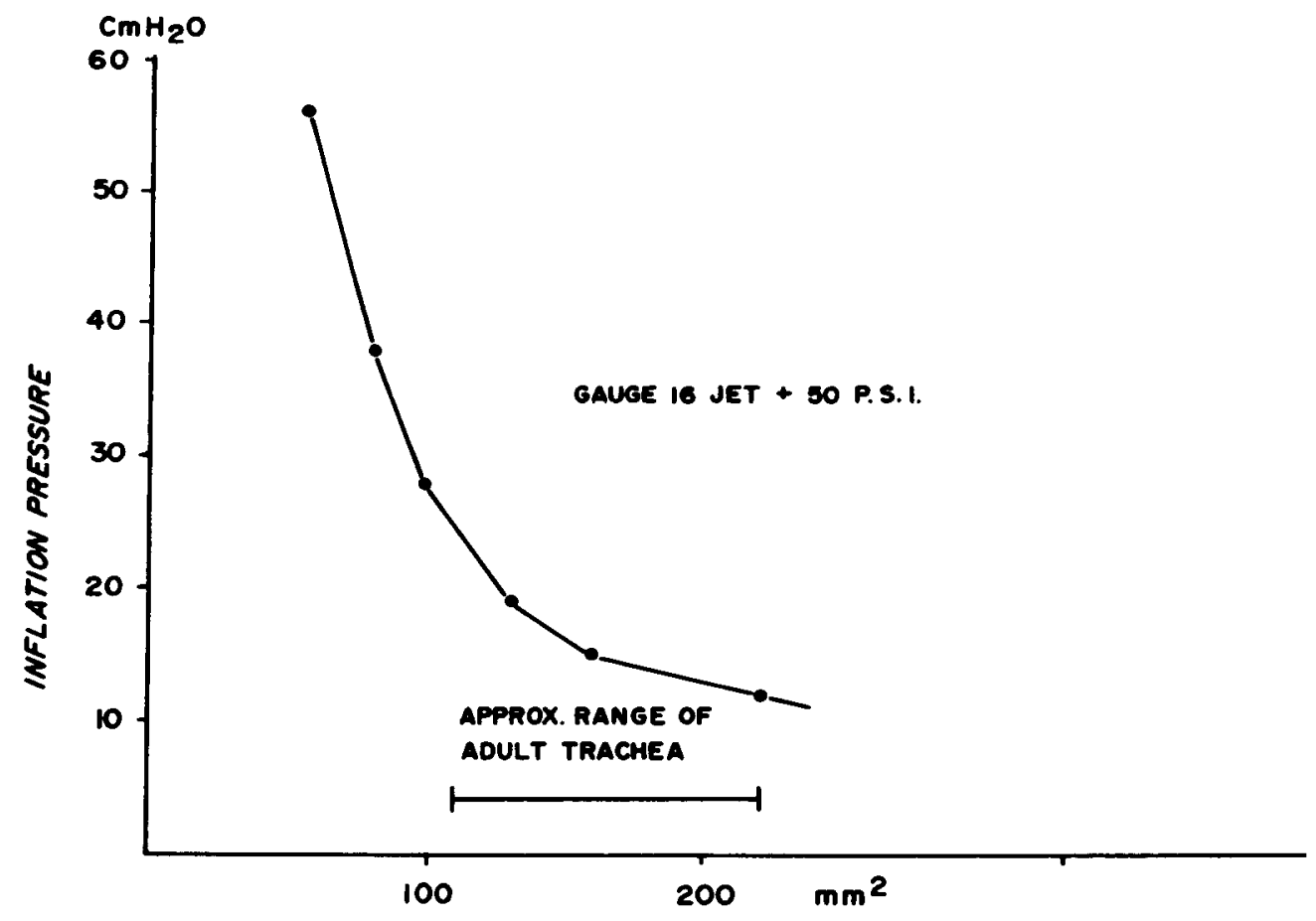

CROSS SECTIONAL AREA OF TUBE

FIgURE 4. Relationship between inflation pressure and the cross-sectional area of tube (trachea) into which a given jet flow is directed.

Entrance into the trachea is verified by the aspiration of air into the syringe. The stilette is then withdrawn a few millimeters so as to bring the tip of the stilette into the plastic sleeve. Air aspiration is repeated and the complete length of the plastic cannula is then advanced into the trachea. After withdrawal of the stilette needle, the syringe is firmly attached to the plastic cannula and air aspiration is repeated to ascertain that the tip of the plastic cannula in its final position is free inside the tracheal lumen. The hub of the cannula is now fixed with adhesive tape to the skin of the neck and the pressure tubing is attached to the cannula. Once this is done, the patient is given a paralysing dose of a muscle relaxant (usually succinylcholine) and, when paralysis is effective, oxygen at a pressure of about 50 p.s.i. is applied intermittently to the jet, providing intermittent positive pressure ventilation. Anaesthesia is maintained with intravenous agents and further muscle relaxant as required.

\section{Nasotracheal Jet}

After induction with a sleeping dose of thiopentone, muscular relaxation with succinylcholine and pre-oxygenation by mask, the plastic catheter inside its sheath, consisting of a 14-gauge disposable catheter, is introduced through the nose into the pharynx. The larynx is then exposed with a Macintosh laryngoscope and the tip of the catheter is manipulated through the glottis, with the help of an intro- 
ducing forceps if necessary, and advanced into the trachea until the $10 \mathrm{~cm}$ mark has reached the glottis. The outer catheter is then pulled back, leaving only the small polyethylene tubing inside the larynx and trachea. The laryngoscope is then re-introduced and the position of the plastic catheter is adjusted so that the $10 \mathrm{~cm}$ mark is situated just proximal to the vocal cords. In this position, the catheter is taped firmly at the nostril and the outer end is taped at a second point to the patient's forehead. The pressure tubing is then attached and jet ventilation commenced.

\section{Pulmonary Ventilation}

In order to provide intermittent positive pressure ventilation, the jet must be interrupted at a rate of 12 to 16 times per minute and at a ratio of inspiration to expiration of $1: 1$ or 1.5. Interruption of the jet can be done either with a simple hand valve or with a Bird Mark II ventilator. Although pressure may be supplied from the oxygen pipe line, an oxygen tank with a variable reducing valve provides better adjustment of the ventilation. In adults, a pressure of 40 to 50 p.s.i. is initially applied to the jet and either increased or reduced depending upon the chest excursions observed.

There is a pressure gradient across the Bird Mark II ventilator and a pressure gauge at the outlet of the ventilator will provide an indicator for the pressure applied to the jet. ${ }^{4}$

\section{Operative Laryngoscopy}

When the patient is ventilated satisfactorily, endoscopy can commence. It is important that during introduction of the surgeon's laryngoscope the patient be completely paralysed and, furthermore, we prefer to interrupt ventilation during this time. If the patient is closing the glottis in response to stimulation or if, during a difficult introduction, the upper airway should become occluded to expiration, pressure in the subglottic airway can rise to a dangerous level, leading to alveolar rupture, tissue emphysema and pneumothorax. Once the glottis is exposed this can no longer happen even if relaxation is incomplete.

With the laryngoscope in place and secured by a holding device the surgeon has unrestricted access to the larynx; with the nasotracheal technique only a small bore polyethylene tubing crosses from the nasopharynx into the trachea. The vocal cords can be kept absolutely still, since the air flow during expiration is not greater than with normal quiet breathing. Blood from the operative site is usually blown out by the excess flow from the jet and, with additional suction, bleeding has been no problem in our experience. Adequate pulmonary ventilation can be provided with either a transtracheal cannula or a nasotracheal catheter used as jet. With the transtracheal technique, pressures ranging from 40 to 80 p.s.i. were used and arterial $\mathrm{PCO}_{2}$ determinations at the termination of the surgical procedure indicated that the majority of patients were markedly to moderately over-ventilated (Figure 5). Only 3 out of 15 patients had mild hypercarbia. $\mathrm{PCO}_{2}$ changes were independent of the duration of the procedure. Similar results were obtained in 22 patients where a nasotracheal catheter was used (Figure 6) and only four of these patients had mild hypercarbia, the highest level being $52 \mathrm{mmHg}$. 


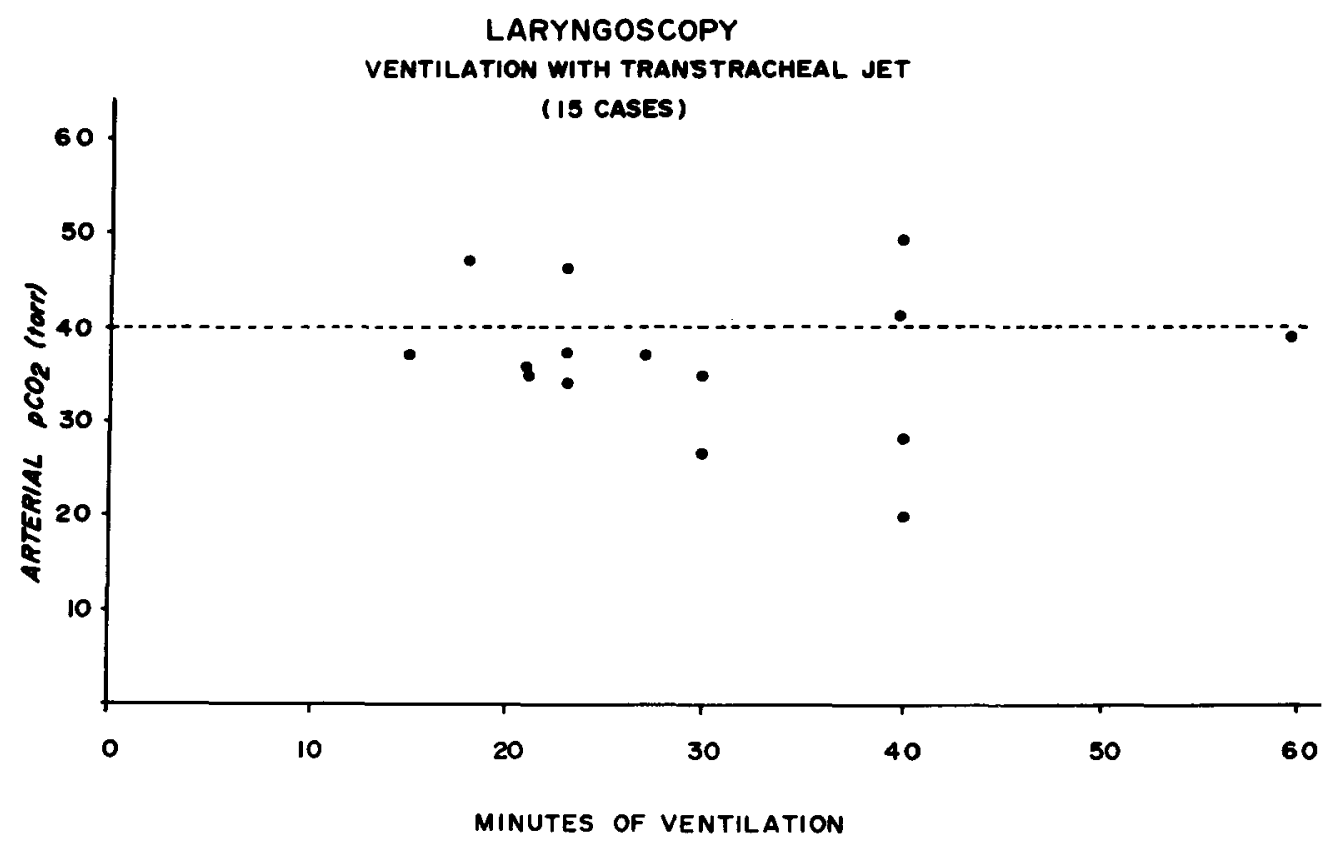

Figure 5. Arterial $\mathrm{PCO}_{2}$ determined just prior to termination of transtracheal ventilation in 15 patients undergoing endolaryngeal surgery.

\section{Complications}

The only major complication is massive tissue emphysema which can occur either when the jet is not inside the tracheal lumen or when the outllow of gas from the glottis is obstructed while the ventilation continues. This latter complication occurred once in this series. Upon recognition, the patient was immediately intubated and ventilation with oxygen continued while needles were placed in both chest cavities to relieve bilateral pneumothorax. Since the emphysema was produced mainly by oxygen which is fairly rapidly absorbed from tissues, the swelling did recede quickly and in this patient only minor degrees of tissue emphysema were detectable on X-ray eight hours after the accident. This patient underwent a laryngoscopy for removal of multiple vocal cord polyps six weeks later with the same technique, without complications. Adequate muscular relaxation and temporary interruption of ventilation during introduction of the laryngoscope by the surgeon would have avoided this complication.

Both techniques are safe as long as the jet discharges into the trachea. It is therefore important to adhere to the technique in detail, particularly with the transtracheal approach where a tightly fitting syringe and repeated aspirations when the needle is in its final position are imperative to make sure that the needle tip is in fact freely in the lumen of the trachea. Prior to the introduction of the surgical laryngoscope, the patient should be ventilated long enough to ascertain that pulmonary ventilation is not only present but adequate.

Following transtracheal ventilation in an earlier series ${ }^{5}$ we had observed mild tissue emphysema in the neck in some patients. This can be avoided by keeping 


\section{LARYNGOSCOPY}

VENTILATION WITH NASOTRACHEAL JET

( 22 CASES)

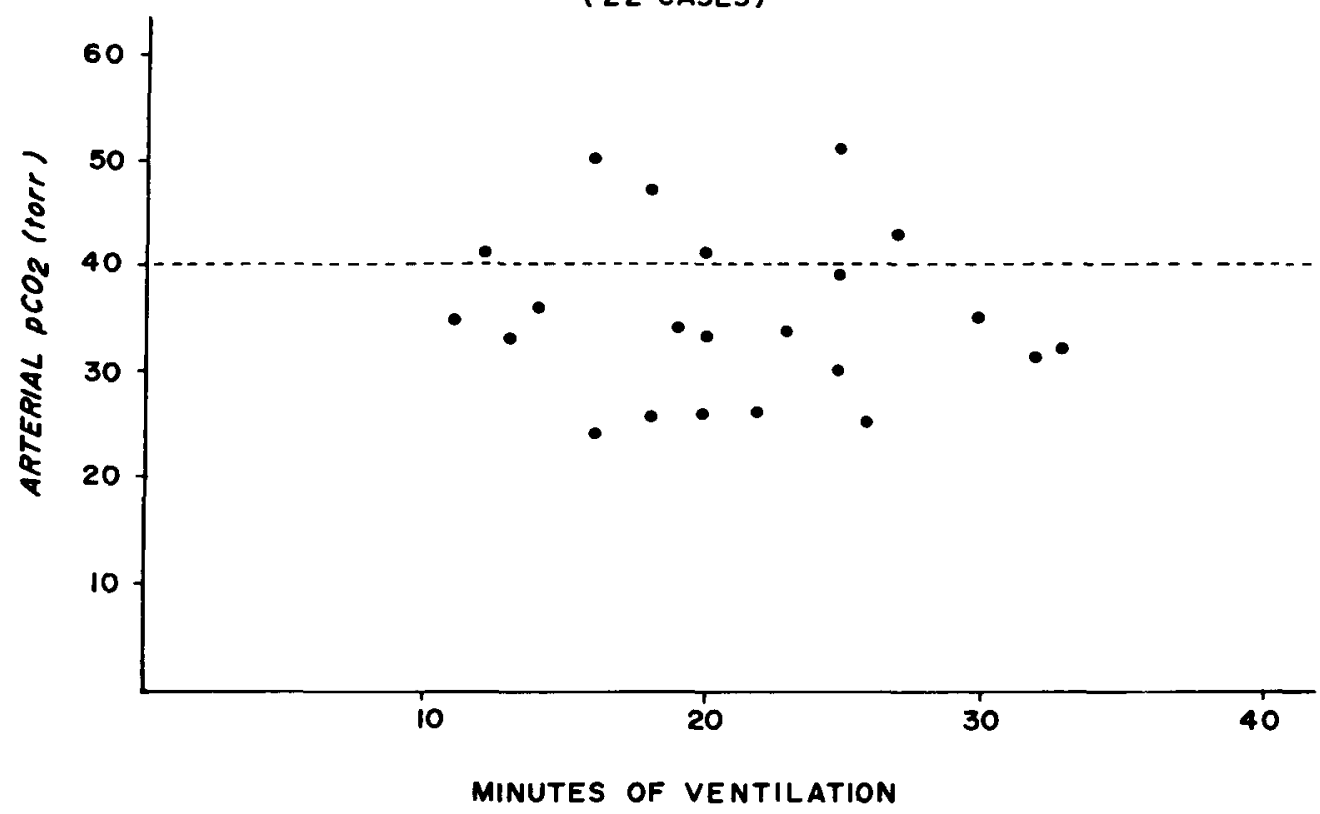

Figure 6. Arterial $\mathrm{PCO}_{2}$ determined just prior to determination of nasotracheal jet ventilation in 22 patients undergoing endolaryngeal surgery.

the needle in place until the patient is fully awake and by digital compression of the puncture site for a few minutes after removal of the needle, particularly if the removal has stimulated coughing. The transient occurrence of blood-streaked sputum was observed twice in the earlier series but has not occurred in the cases presented here.

In the non-paralyzed patient, anaesthetized or awake, the jet will elicit a cough response each time it is turned on. This response can be controlled by topical anaesthesia. The tracheal mucosa is probably less traumatized by this technique than by the usual cuffed endotracheal tube and there was no discomfort postoperatively which could be attributed to the anaesthetic technique.

\section{Discussion}

The use of a nasotracheal catheter as intratracheal jet would seem to be more appealing to anaesthetists and surgeons, and is presently our routine for microlaryngeal surgery. This technique has now been used in 59 cases, providing uniformly satisfactory conditions for the endoscopic procedure.

The transtracheal technique has advantages with extensive laryngeal lesions or supraglottic lesions (e.g., epiglottic cysts) where access to the larynx may initially be difficult. The transtracheal approach is preferred over the puncture of the cricothyroid membrane; it brings the jet further away from the larynx, avoiding 
the chance that it may accidentally be grasped by a biopsy forceps and it makes it possible to enter the trachea more tangentially, thus avoiding kinking of the needle between tissue planes. Occasionally it may be desirable to puncture the trachea some distance below the cricoid in order to bypass a subglottic lesion. ${ }^{4}$ The use of a curved plastic cannula, as proposed by Jacobs² would appear to have some advantages over a straight needle, but such a cannula is presently not available.

In our opinion, jet ventilation represents a most satisfactory solution for endolaryngeal surgery. Transtracheal ventilation is also useful for emergency ventilation and in cases of inspiratory upper airway obstruction, glottic or supraglottic, where laryngoscopy may be difficult or impossible.

For the nasotracheal jet a tubing of sufficient stiffness is required; soft plastic tubing will oscillate when pressure is applied and will also recoil, causing it to slip out of the trachea. Polyethylene tubing proved most satisfactory; it is commercially available in rolls and can be cut to any desired length. The nasotracheal route allows more secure fixation, but an orotracheal approach could also be used.

Carden ${ }^{1}$ has developed a technique which uses a short stub of tracheal tube with a cuff to anchor the jet in the trachea. This approach has the additional advantage that the jet discharges into the smaller tube, providing higher inflation pressures at a lower pressure applied to the jet. However, the jet may be more difficult to introduce, particularly in cases where lesions have produced a narrowing or distortion of the glottis.

The introduction of a jet into the laryngoscope similar to Sanders technique of ventilation during bronchoscopy, ${ }^{4}$ either by attachment to the rim of the laryngoscope or into a light carrier channc $l^{: 3}$ will also provide adequate pulmonary ventilation. However, the patient can then only be ventilated once the laryngoscope is in place and the glottis open. Furthermore, positive pressure is generated proximal to the larynx, causing blood and debris from the operative site to be blown into the trachea.

\section{SuMMary}

Adequate pulmonary ventilation can be obtained in completely relaxed patients under intravenous general anaesthesia by applying the injector principle directly to the human trachea. A jet of oxygen is introduced into the trachea by a transtracheal approach, using a 14- or 16-gauge plastic intravenous cannula or by the nasotracheal route, employing a long polyethylene tube corresponding to a 15 gauge intravenous cannula. The latter technique is preferred for routine procedures. Intermittent interruption of jet flow with a Bird Mark II ventilator provides intermittent positive pressure ventilation. The theoretical basis for this technique is outlined and anaesthetic procedure is described. For microscopic endolaryngeal surgery, this approach provides excellent conditions, imposing no restrictions on the operative field or on the duration of surgery.

\section{RÉSUMÉ}

On peut obtenir une ventilation pulmonaire adéquate chez des malades complètement relachés sous anesthésie générale par voie endoveineuse en appliquant le 
principe d'injecteur directement dans la trachée de l'humain. Un jet d'oxygène est introduit dans la trachée par voie transtrachéale en employant une canule intraveineuse en plastique No 14 ou 16 ou par voie naso-trachéale en employant un long tube en polyéthylène correspondant à une canule intraveineuse no 15 . Cette dernière technique, pour les cas de routine, est préférable. L'interruption intermittente du courant en jet avec un ventilateur Bird marque II assure une ventilation à pression positive intermittente. Nous décrivons la procédure anesthésique et mentionnons la base théorique de cette technique. Pour la chirurgie microscopique endolaryngée, cette façon de procéder donne de bons résultats ne limitant ni le champ opératoire ni la durée de la chirurgie.

\section{REFERENCES}

1. Carden, E. \& Crutchfield, W. Anaesthesia for microsurgery of the larnyx. Canad. Anaes. Soc. J. 20:378 (1973).

2. JACOBs, H.B. Emergency percutaneous transtracheal catheter and ventilator. J. Trauma. 12: $50(1972)$.

3. Rajagopalan, R., Smith, F., \& Ramachandran, P.R. Anaesthesia for microlaryngoscopy and definitive surgery. Canad. Anaes. Soc. J. 19: 83 (1972).

4. Spoerel, W.E. \& Grant, P.A. Ventilation during bronchoscopy. Canad. Anaes. Soc. J. 18: 178 (1971).

5. Spoerel, W.E., Narayanan, P.S., \& Singh, N.P. Transtracheal ventilation. Brit. J. Anaesth. 43: 932 (1971).

6. Spoerel, W.E., Singh, N.P., \& SAWHNEY, K.L. Transtracheale Beatmung fuer endolaryngeale Eingriffe. Der Anaesthesist. 21: 59 (1972). 